\title{
Distal Pup Cues Evoke Dopamine Responses in Hormonally Primed Rats in the Absence of Pup Experience or Ongoing Maternal Behavior
}

\author{
Veronica M. Afonso, Waqqas M. Shams, Daniel Jin, and Alison S. Fleming \\ Department of Psychology, University of Toronto, Mississauga, Ontario L5L 1C6, Canada
}

\begin{abstract}
During the early postpartum period or following estrogen/progesterone administration, pups elicit maternal behavior accompanied by a robust dopamine (DA) response in the nucleus accumbens (NAC) of female rats (Afonso et al., 2009). To determine whether DA responds to ostensibly "salient" stimuli in the absence of consummatory behaviors, we examined NAC shell DA responses during restricted (stimuli placed in a perforated box), and unrestricted access to pup and food stimuli. Microdialysis samples were collected from female rats that were either cycling and postpartum (Experiment 1), or after ovariectomy and treated with empty and hormone-filled capsules (Experiment 2). Relative to nonprimed controls, hormonally primed females had suppressed basal DA concentrations and facilitated pup-evoked DA responses, regardless of stimulus access condition. In contrast, food-evoked DA responses were unchanged by hormonal priming and were greater when females consumed food compared with distal (restricted) exposure to food. During pup and food restriction conditions, the lack of any "appetitive" behavioral differences, even in pup experienced postpartum females, was surprising. In Experiment 3, we confirmed that postpartum dams allocated time equivalently to restricted pup and food stimuli, even after pup deprivation. This was in sharp contrast to the effects of deprivation during the unrestricted access phase. Together, our data demonstrated that, in hormonally primed females, distal pup cues could evoke DA responses without prior stimulus experience, ongoing maternal (behavioral) responses, or clear evidence of robust pup saliency. The results suggest that NAC DA response reflects a state of responsiveness related to basal DA suppression in the hormonally primed female rat.
\end{abstract}

\section{Introduction}

The maternally inexperienced mother rat shows the full repertoire of maternal behavior during the end of pregnancy, birthing, and first encounters with her young (Wiesner and Sheard, 1933; Fleming and Rosenblatt, 1974; Numan and Insel, 2003). In the absence of hormonal changes, virgin rats avoid pups on initial exposure (Li and Fleming, 2002; Numan et al., 2006); however, with continuous pup exposure, they show maternal behavior (4-10 d) to foster pups (Rosenblatt, 1967; Fleming and Rosenblatt, 1974; Orpen and Fleming, 1987). The administration of hormones associated with late pregnancy and parturition facilitates a rapid onset (1-6 d) of maternal responsiveness (Moltz et al., 1970; Krehbiel and LeRoy, 1979; Mayer and Rosenblatt, 1979, 1980, 1987; Bridges, 1984, 1990).

Estradiol and progesterone enhance mothering by acting on both hypothalamic and mesolimbic mechanisms (Numan et al.,

Received April 30, 2012; revised 0ct. 20, 2012; accepted 0ct. 31, 2012.

Author contributions: V.M.A. and A.S.F. designed research; V.M.A., W.M.S., and D.J. performed research; V.M.A. contributed unpublished reagents/analytic tools; V.M.A., W.M.S., D.J., and A.S.F. analyzed data; V.M.A. and A.S.F. wrote the paper.

This work was supported by a Natural Science and Engineering Research Council discovery grant and Canadian Research Council grant to A.S.F. We thank the University of Toronto, Mississauga vivarium staff for help in maintaining animals in good health.

The authors declare no competing financial interests.

Correspondence should be addressed to either Dr. Veronica M. Afonso or Dr. Alison S. Fleming, Department of Psychology, University of Toronto Mississauga, 3359 Mississauga Road N, Mississauga, ON L5L 1C6, Canada, E-mail: veronica_afonso@hotmail.com or alison.fleming@utoronto.ca.

DOI:10.1523/JNEUROSCI.2081-12.2013

Copyright $\odot 2013$ the authors $\quad 0270-6474 / 13 / 332305-08 \$ 15.00 / 0$
2006). The nucleus accumbens (NAC), a terminal site of the mesolimbic dopamine (DA) system, regulates stimulus salience, reinforcement learning, and motor output in a variety of motivational contexts (Graybiel et al., 1994; Berridge and Robinson, 1998; Cagniard et al., 2006). On initial pup exposure, the recently parturient mother rat shows a substantial DA elevation, an observation not seen in virgin animals, even after experience (Hansen et al., 1991a,b, 1993; Champagne et al., 2004; Olazábal et al., 2004; Ferris et al., 2005; Afonso et al., 2009, 2011). The two groups also differ in baseline DA, with levels considerably reduced in postpartum rats (Afonso et al., 2009, 2011). A similar baseline DA suppression and pup-stimulated DA elevation are obtained in virgin animals treated with hormones (Afonso et al., 2009, 2011). Although ovarian hormones can bias the DA system to respond to pup stimuli in the absence of pup experience, undetermined is whether pup-evoked DA relates to pup saliency alone or to the actual expression of maternal behavior, as DA responses correlate to licking behavior (Afonso et al., 2009, 2011).

The present study determined whether: (1) distal pup cues (e.g., olfactory, visual, auditory emanating from a Plexiglas box with holes) provoke the same DA release pattern as found with unrestricted pup interactions; (2) ovarian hormones in the absence of pup experience contribute to restricted pup-evoked DA responses; and (3) selectivity exists in restricted pup-evoked DA responses by comparisons with restricted food responses. In a nonhomecage chamber, microdialysis samples were collected from the NAC shell of (1) virgin and postpartum (Experiment 1) 
or (2) pup-naive ovariectomized (OVX) sham-and hormonetreated (Experiment 2) virgin female rats interacting with pup and food stimuli under restricted and unrestricted access. Previously, postpartum females attended predominately to pups when given simultaneous unrestricted access to pups and food in the dialysis chamber (Afonso et al., 2009). Using a much larger apparatus compared with the dialysis chamber, in Experiment 3, postpartum rats were given simultaneous restricted access to pups and food, followed by unrestricted access to these stimuli. Performed after deprivation conditions, this experiment was designed to alter the animals' specific "motivational" state as reflected by differential time spent in proximity to pups versus food in unrestricted phases.

\section{Materials and Methods}

\section{Subjects}

Virgin Sprague Dawley female rats (225-300 g), obtained from Charles River, were individually housed in Plexiglas shoebox cages $(21 \mathrm{~cm}$ high $\times$ $26 \mathrm{~cm}$ wide $\times 38 \mathrm{~cm}$ deep), given wooden shavings for bedding. Purina Rat Chow and water were available ad libitum. Animals were housed in a colony room maintained on a 12:12 h light/dark cycle with lights on $8 \mathrm{am}$ to $8 \mathrm{pm}$, at $\sim 24^{\circ} \mathrm{C} \pm 1^{\circ} \mathrm{C}$.

\section{Habituation to apparatus and food}

Before experimental manipulations, all females were given 4 Honey Nut Cheerios daily for a week in their homecage. Then for $5 \mathrm{~d}$ ( $1 \mathrm{~h}$ sessions) during which they were given 4 Cheerios, females were habituated to the dialysis cage (Experiments 1 and 2; clear circular plastic; $24.77 \mathrm{~cm}$ diameter, $29.8 \mathrm{~cm}$ height, with two stainless steel food dispensers and plastic floor), or to the large testing apparatus (Experiment 3; clear rectangular Plexiglas; $34 \mathrm{~cm}$ wide, $108 \mathrm{~cm}$ length, $38 \mathrm{~cm}$ height, with corn cobcovered floor).

\section{Experiments 1 and 2: general methods}

Microdialysis procedure. Rats were anesthetized using a 2:2 isofluorane/ oxygen ratio for all surgical procedures. Females were stereotaxically implanted with a unilateral guide cannula with a stylet $(15 \mathrm{~mm}$ in length, Bioanalytical Systems) aimed above the NAC shell (flat skull; $1.7 \mathrm{~mm}$ caudal to bregma, $0.5-1.0 \mathrm{~mm}$ lateral to midline, $6.9-7.3 \mathrm{~mm}$ beneath the surface of the skull) (Paxinos and Watson, 1986). During sampling, a probe ( $320 \mu \mathrm{m}$ OD, $2 \mathrm{~mm}$ length, cutoff 20,000 Da, Bioanalytical Systems) extending $2 \mathrm{~mm}$ below the guide was attached to tubing; a needle dispensed the collection samples at a rate of $1 \mu \mathrm{l} / \mathrm{min}$ in $8 \mathrm{~min}$ bins into refrigerated vials $\left(4^{\circ} \mathrm{C}\right)$ containing a standard antioxidant $(2.5 \mathrm{~mm}$ ascorbic acid in $0.9 \%$ saline, Sigma). The dialysis cage had limited space but allowed freedom of movement in all directions while maintaining the integrity of infusion lines. A counterbalanced arm and tethering system kept test lines of the animal's reach while permitting the animal to rise and stretch ad libitum.

Stimuli presentation during microdialysis. After probe placement into the guide cannula, baseline samples were collected (15 samples, 120 min). After this basal sampling, pups or food, counterbalanced during the restricted phase, were presented to the female in a secured Plexiglas box $(6 \times 7.8 \times 7.9 \mathrm{~cm}$, with perforated holes $)$; hence, females had only restricted, distal exposure to the stimuli. Stimuli consisted of donor pups ( 2 males and 2 females that were postnatal day $2-4$, warm and recently fed) or food ( 40 Cheerios in the box). One of the boxed stimuli would be available for $16 \mathrm{~min}$ (i.e., two samples collected) followed by a $16 \mathrm{~min}$ period with no stimulus before the second boxed stimuli was available for $16 \mathrm{~min}$.

The restricted phase was followed by unrestricted access to pups and then food, not counterbalanced. The unrestricted phase first consisted of 16 min availability of the pups (same pups as in the box) placed on shredded paper towel (nesting material) in one of the food dispensers. This was followed by $16 \mathrm{~min}$ of no stimulus, and then 2 Cheerios were placed directly on the chamber floor and after an $8 \mathrm{~min}$ period another 2 Cheerios were placed into the chamber. Food-stimuli were eaten within 1 min during these two 8 min sampling bins. Digital video recording collected behavioral data (see Figs. $2 B, 4 B$ for the sampling procedure).

HPLC. After collection of the samples, DA concentrations were determined with HPLC. Briefly, a BAS 460 HPLC system with electrochemical detection (Bioanalytical Systems) was used together with a Uniget C-8 reverse phase column (catalog no. 8949). The mobile phase consisted of buffer [0.1 m monochloroacetic acid, $0.5 \mathrm{~mm} \mathrm{Na-EDTA,} 0.15 \mathrm{~g} / \mathrm{L} \mathrm{Na}-$ octylsylfonate, and $10 \mathrm{~nm}$ sodium chloride, $\mathrm{pH}$ 3.1], acetonitrile and tetrahydrofuran (Sigma) at a ratio 94:3.5:0.7. The flow rate was $0.5 \mathrm{ml} /$ $\mathrm{min}$, and the working electrode (Iniget $3 \mathrm{~mm}$ glassy carbon, BAS P/N MF-1003) was set at $700 \mathrm{mV}$ versus $\mathrm{Ag} / \mathrm{Ag} / \mathrm{Cl}$. Detection gain was $1.0 \mathrm{nA}$, filter was $0.2 \mathrm{~Hz}$, and the detection limit was set at $500 \mathrm{nA}$. Of the $8 \mu \mathrm{l}$ of collected per sample, $5 \mu \mathrm{l}$ was directly injected into the HPLC system for analysis. The remaining $3 \mu \mathrm{l}$ of the sample was used in combination with external standards of DA (Sigma) to quantify and identify the peaks on the chromatographs. The retention times for DA were $\sim 3.32$ min under the set conditions.

Probe placement. For an animal to be included in the statistical analysis, the guide cannula had to end above the NAC and between 0.3 and 1.0 $\mathrm{mm}$ from midline. Figure 1 shows the anatomical placements of the "active" zones of the probe.

\section{Experiment 1: parity methods}

Females were either placed with males for mating ( postpartum, $n=5$ ) or left alone (virgin and cycling, $n=6$ ) in their homecages for $10 \mathrm{~d}$. Pregnant (d14-16 gestation) and cycling females had guide cannulae placed into the NAC shell. Sampling began $24 \mathrm{~h}$ after parturition for postpartum females. Dialysate samples were collected from a cycling female on the same day as a postpartum dam. During sampling donor pups, rather than their own pups, were used as the pup stimuli.

\section{Experiment 2: hormone treatment methods}

One week after OVX, virgin pup-naive females were randomly assigned to sham $(n=5)$ or hormone $(n=7)$ treatment groups. OVX animals were anesthetized and a single $17 \mathrm{~h}$-estradiol 3-benzoate (E, Sigma) capsule was administered subcutaneously via a $20 \mathrm{~mm}$ SILASTIC implant $(0.078$ in ID $\times 0.125$ in OD; Dow Corning $)$ in the nape region. Two days after the E capsule implants, animals were again anesthetized and an additional 3 progesterone ( $\mathrm{P}$, Sigma) capsules $(40 \mathrm{~mm})$ were administered subcutaneously in the dorsal region. Before implantation, the SILASTIC capsules were sealed with $5 \mathrm{~mm}$ wood piece (CAN Lab) and SILASTIC Medical Adhesive (Dow Corning) after being filled with either $\mathrm{E}$ or P. The $100 \%$ crystalline E- and P-filled portions of the implants were 10 and $30 \mathrm{~mm}$ in length, respectively. The capsules were left to dry for a $24 \mathrm{~h}$ period, after which they were washed in ethanol and incubated for $48 \mathrm{~h}$ in PBS ( $\mathrm{pH}$ 7.0). At the same time points, control rats received empty (unfilled) SILASTIC implants that resembled the hormone-filled capsules. Progesterone capsules were removed $10 \mathrm{~d}$ after implantation and sampling commenced the following day. Previously, the serum E levels with these E treatments were in the range of $75-80 \mathrm{pg} / \mathrm{ml}$, similar to those found during pregnancy $\mathrm{d} 15-22$, whereas the P treatment at 32 $\mathrm{ng} / \mathrm{ml}$ yield less than pregnancy levels of $80 \mathrm{ng} / \mathrm{ml}$ at gestation $\mathrm{d} 4-10$, or $120 \mathrm{ng} / \mathrm{ml}$ at gestations d12-20 (Stern and McDonald, 1989).

\section{Experiment 3: time allocation methods}

Female rats $(\mathrm{N}=16)$ were placed with males for $10 \mathrm{~d}$ of mating. Two days after parturition, time allocation assessments were made from these postpartum females given 20 min tests with simultaneous presentation of pups ( 2 males and 2 females, PND2-5) and food (Cheerio) stimuli, each on opposing sides of the test chamber. For the first $10 \mathrm{~min}$ of the test, females were given restricted access to pups and food, each stimulus in their own perforated box; then for the next $10 \mathrm{~min}$, the boxes were opened (unrestricted). For the food side, during the restricted phase the box contained $\sim 40$ Cheerios, and during the unrestricted phase this box was replace with an open box containing 4 Cheerios.

Females were given two 20 min tests daily: (1) under a nondeprived condition and (2) later in the day after one of four possible deprivation conditions. For the first test of the day, postpartum rats were removed from their homecage and litter and placed in the center of the large chamber for the $20 \mathrm{~min}$ test period. Rats were then placed back into their 


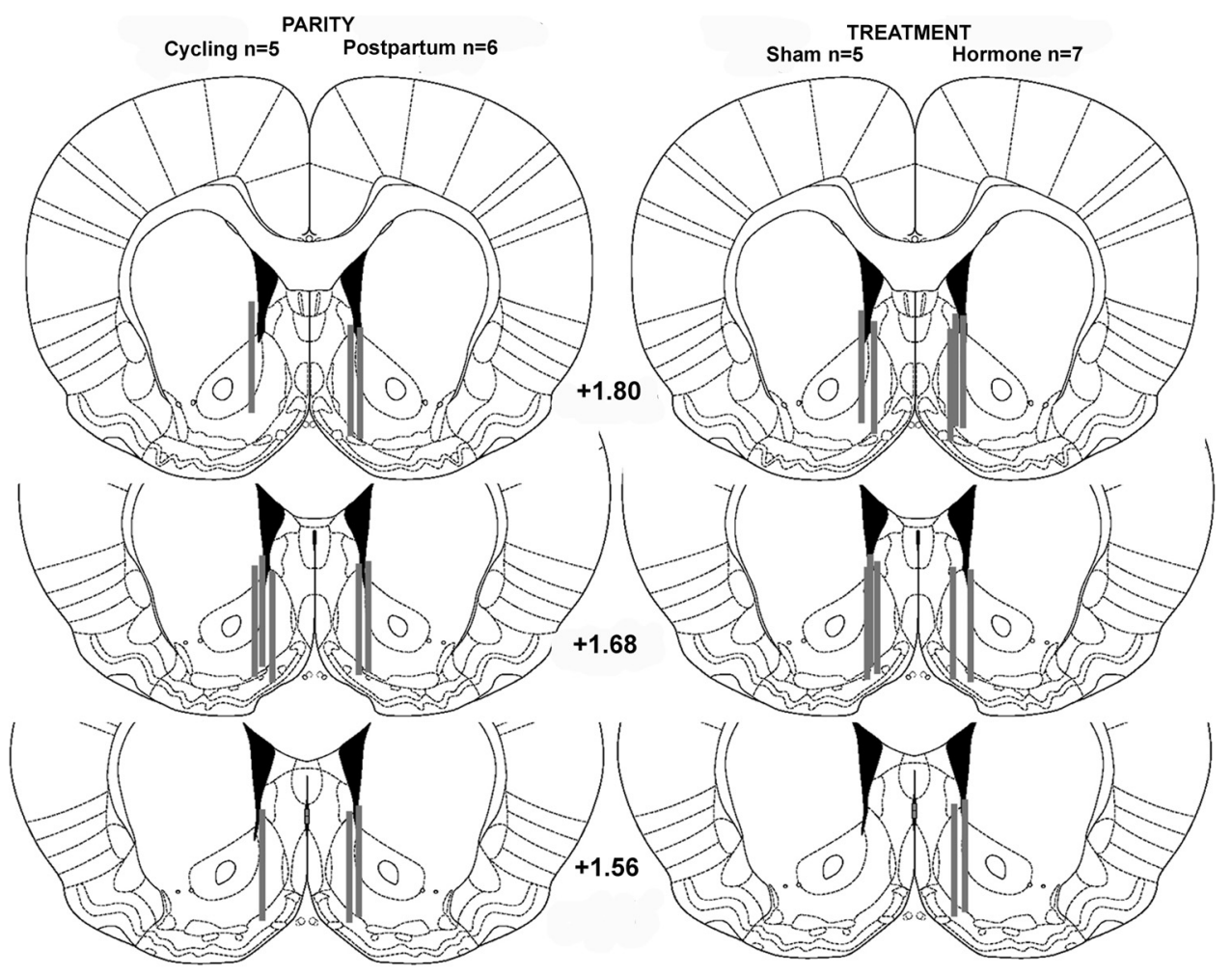

Figure 1. For intact cycling/postpartum (Experiment 1) and OVX sham/hormone-treated (Experiment 2) female rats, schematics of anatomical unilateral placements (anterior to bregma, according to Paxinos and Watson, 1986) of the "active zone" (shaded lines) of microdialysis probes in the nucleus accumbens shell at three different locations.

homecage before a second test was performed. While in their homecage, postpartum rats were deprived of their pups $(\mathrm{P})$ and food $(\mathrm{F})$ for either 5 or $10 \mathrm{~h}$ durations, thus creating four deprivation conditions: 5P5F, 5P10F, 10P5F, and 10P10F. The conditions were counterbalanced across $4 \mathrm{~d}$ so that each female was given a second test under each deprivation condition, which was performed after the nondeprived condition (designated as $0 \mathrm{POF}$ ), performed daily across the $4 \mathrm{~d}$. Based on videotape coding, the time spent with each of the stimuli for the each of the $10 \mathrm{~min}$ access phases was calculated by partitioning the chamber into three equal compartments with the center considered neutral.

\section{Experiments 1 and 2: statistical analyses}

Basal DA. Before the 128 min sampling procedure, which included presentation and removal of various stimuli, basal DA concentrations were obtained from means of three consecutive samples that differed from one another by no $>10 \%$. An independent samples $t$ test was performed on DA concentrations $(\mathrm{pg} / \mu \mathrm{l})$ for both experiments to assess group differences ( parity, cycling vs postpartum [Experiment 1]; or treatment, sham vs hormone [Experiment 2]).

Stimulus-evoked DA. For each experiment to assess stimulus-evoked DA, a 3-factor ANOVA, 2-group (parity, cycling vs postpartum [Experiment 1] or treatment, sham vs hormone [Experiment 2]) $\times 2$ stimulus (pups vs food) $\times 2$ access (restricted vs unrestricted), was performed on DA responses (\% of basal concentrations, averaged across the two samples). For significant interactions, Tukey HSD post hoc analysis was performed on individual means with appropriate corrections. As basal DA measurements differed with hormonal status in both experiments, to investigate further the influence of basal DA levels on DA responses to stimuli for each experiment, we included the basal concentrations as a covariate in the ANOVAs.

Behavior. During microdialysis, we analyzed behavioral differences between the groups under the restricted phase, using a 2 group (parity [Experiment 1] or treatment [Experiment 2]) $\times 2$ stimulus (pups vs food) ANOVA on the time spent on sniffing or touching the box containing either pups or food. In terms of pup stimuli, a second ANOVA was performed to determine the behavioral effects of restricting access to pups. A 2 group (parity or treatment) $\times 2$ access (restricted vs unrestricted) ANOVA was performed on time spent with pup stimuli. Foodrelated behavior during the unrestricted phase was not included in a similar analysis, as females ate the 2 Cheerios within $1 \mathrm{~min}$ in each of the two $8 \mathrm{~min}$ bins, thereby eliminating the presence of the stimuli.

\section{Experiment 3: statistical analysis}

A 2 (access: restricted vs unrestricted) $\times 2$ (stimuli: pups vs food) $\times 5$ (conditions: $0 \mathrm{P} 0 \mathrm{~F}$ vs $5 \mathrm{P} 5 \mathrm{~F}$ vs $5 \mathrm{P} 10 \mathrm{~F}$ vs, $10 \mathrm{P} 5 \mathrm{~F}$ vs $10 \mathrm{P} 10 \mathrm{~F}$ ) repeatedmeasures ANOVA was performed on the duration ( $\mathrm{sec}$ ) a postpartum rat spent on a given stimulus side. The nondeprived condition (i.e., OP0F) was performed daily before a given deprivation conditions, and we averaged the time spent with each stimulus across the $4 \mathrm{~d}$ for the $0 \mathrm{P} 0 \mathrm{~F}$ condition.

\section{Results}

\section{Experiment 1: parity effects}

Basal DA

$t$ tests revealed that postpartum dams had significantly reduced basal DA concentrations compared with cycling females $\left(\left[t_{(9)}=2.46, p=0.04\right]\right.$, Fig. $\left.2 A\right)$. The time course of the DA responses ( $\%$ of basal concentrations) after basal collection is shown in Figure $2 B$.

\section{Stimulus-evoked DA}

The ANOVA for stimulus-evoked DA revealed significant main effects of parity $\left[F_{(1,9)}=12.34, p=0.007\right]$ and access $\left[F_{(1,9)}=\right.$ $14.52, p=0.004]$. Postpartum dams had increased DA responses compared with cycling females; and compared with restriction, unrestricted access to stimuli produced increased DA responses in all females. There were also significant interactions of parity $X$ stimulus $\left[F_{(1,9)}=13.36, p=0.005\right]$ and stimulus $\times$ access $\left[F_{(1,9)}=5.47, p=0.044\right]$. Post hoc analyses showed that postpartum females had increased pup-evoked DA responses compared 
with the cycling group (Fig. 3A), regardless of access type. During restriction, postpartum females had increased pupevoked compared with food-evoked DA responses; and during the unrestricted phase, cycling females showed the reverse. Both parities showed increased DA responses to unrestricted compared with restricted access to food (Fig. 3A). When basal concentrations were partialled out, these effects remained significant.

\section{Behavior}

The parity $\times$ stimulus ANOVA revealed no significant effects, demonstrating that during restricted access females sniff and touch the two boxes equivalently, regardless of parity or stimulus. The parity $X$ access ANOVA revealed a significant interaction $(p<0.001)$. During unrestricted access to pups, the postpartum females spent more time with pups (i.e., sniffing, retrievals, hovering, licking, mouthing) than during restricted pup-access and compared with the cycling group (Fig. 3B).

\section{Experiment 2: hormone treatment effects \\ Basal DA}

As with the parity effect, the $t$ test performed on DA concentrations revealed that hormone-treated females had significantly reduced basal DA release compared with sham females $\left[t_{(10)}=5.00\right.$, $p=0.001]$. See Figure $4 A$ for basal data and Figure $4 B$ for time course of DA responses (percentage over basal).

\section{Stimulus-evoked DA}

The ANOVA revealed significant main effects of treatment $\left[F_{(1,10)}=30.80, p<0.001\right]$ and access $\left[F_{(1,10)}=26.30, p<\right.$ $0.001]$. Hormone-treated females had increased DA responses compared with sham females; and compared with restriction, unrestricted access to the stimuli produced increased DA responses in all females. There were also significant interactions of treatment $\times$ stimulus $\left[F_{(1,10)}=5.57, p=0.040\right]$ and treatment $\times$ access $\left[F_{(1,10)}=10.14, p=0.010\right]$. Post hoc analyses showed similar results to Experiment 1 in that hormone-treated females had increased pup-evoked DA responses compared with the sham group, regardless of access type. Like Experiment 1, hormone-treated females had increased pup-evoked compared with food-evoked DA responses during the restricted phase; and during the unrestricted phase, sham-treated females showed the reverse. Both treatment groups showed increased DA responses to unrestricted food compared with restricted access (Fig. 5A). Unlike postpartum females, hormone-treated females had increased DA responses to unrestricted pup access compared with the restricted condition. Different from earlier effects showing parity differences, in this hormone experiment, when basal concentrations were partialled out of the analyses, all significant effects were eliminated.

\section{Behavior}

The treatment $\times$ stimulus ANOVA revealed no significant results, demonstrating that during restricted access females sniff and touch the two boxes equivalently, regardless of treatment or stimulus. The treatment $\times$ access ANOVA revealed a significant interaction $(p<0.001)$. During unrestricted access to pups, the hormone-treated females spent more time with pups (i.e.,

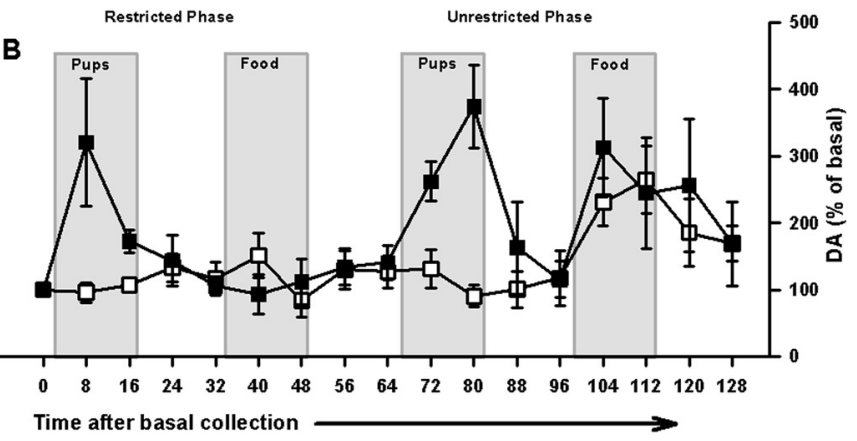

Figure 2. For intact cycling $(n=5)$ or postpartum $(n=6)$ female rats (Experiment 1), in vivo DA assessments before and during restricted and unrestricted access to pup and food stimuli. $A$, Basal DA level data (mean $\pm S E M$ ) represent the average DA concentration of 3 samples collected before any stimuli exposure. Postpartum females had decreased basal DA concentration 列
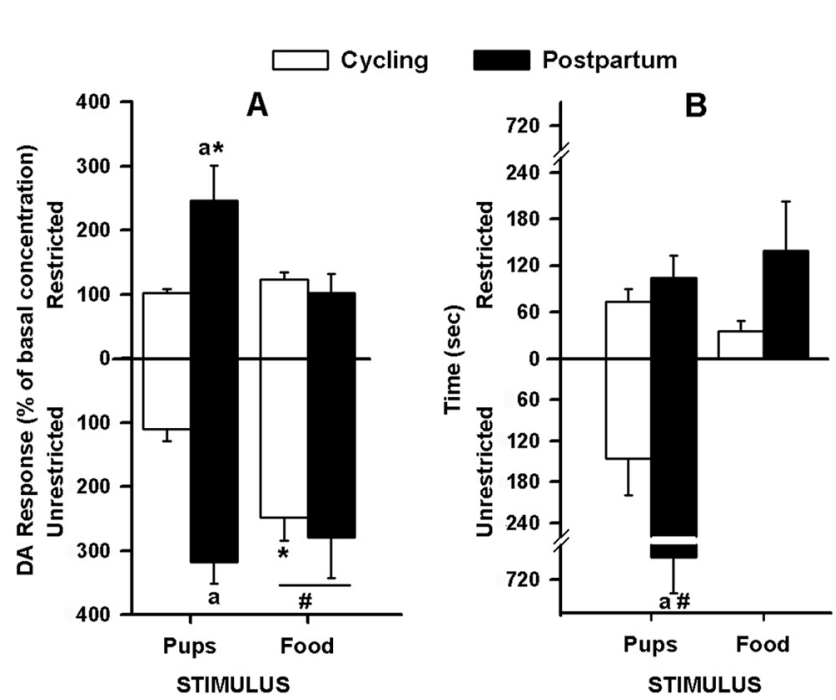

Figure 3. Parity, stimulus, and access had selective effects on (A) DA that was unrelated to (B) behavior in the intact female rat (Experiment 1). $A$, DA response data (mean \pm SEM) represent average percentage of basal concentration. Postpartum $(n=6)$ females during restriction had increased pup-evoked compared with food-evoked DA, and compared with the cycling $(n=5)$ group had increased pup-evoked DA, regardless of access type. When unrestricted, cycling females had increased food-evoked compared with pup-evoked DA responses. In all females, DA responses to unrestricted food were increased compared with restricted access. $\boldsymbol{B}$, Time spent (mean \pm SEM) in behaviors directed toward each of the restricted stimuli and during unrestricted pup access. Among postpartum dams, but not among cycling controls, the time spent with unrestricted access to pups was significantly greater than the time spent with pups in the box. ${ }^{a} p<0.05$, parity difference for pup stimuli during a given access. ${ }^{\#} p<$ 0.05 , access difference for a given parity and stimulus. ${ }^{*} p<0.05$, stimulus difference for a given parity and access.

sniffing, retrievals, hovering, licking, mouthing) than during restricted pup access and compared with the cycling group (Fig. 5B).

\section{Experiment 3: time allocation}

The ANOVA showed significant main effects of stimulus $\left[F_{(1,48)}=15.22, p=0.002\right]$ and condition $\left[F_{(4,48)}=6.95, p<\right.$ $0.001]$; and, interactions of access $\times$ stimulus, $\left[F_{(1,48)}=19.95\right.$, $p=0.001]$, access $\times$ condition $\left[F_{(4,48)}=7.14, p=0.001\right]$, stimulus $\times$ condition $\left[F_{(4,48)}=3.61, p=0.012\right]$, and access $\times$ stimulus $\times$ condition $\left[F_{(4,48)}=5.90, p=0.001\right]$. Tukey post hoc analysis, performed on individual means with appropriate corrections, revealed that only after 5 or $10 \mathrm{~h}$ of deprivation from the 


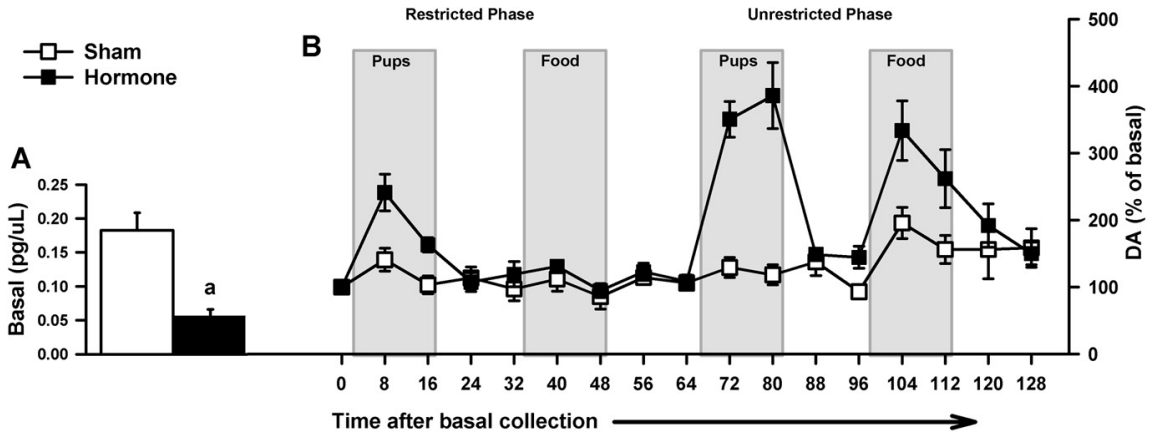

Figure 4. For OVX sham-treated ( $n=5$ ) or hormone-treated ( $n=7$ ) female rats (Experiment 2), in vivo DA assessments before and during restricted and unrestricted access to pup and food stimuli. $A$, Basal DA level data (mean $\pm S E M$ ) represent the average DA concentration of 3 samples collected before any stimuli exposure. Hormone-treated females had decreased basal DA concentrations compared with their sham controls: ${ }^{a} p<0.05$, treatment difference. $\boldsymbol{B}$, After basal collection, the time course for in vivo $D A$ responses relative to basal $D A$ concentrations (mean $\pm S E M$ percentage of basal concentration) during restricted access to pups and food (counterbalanced); and unrestricted access to pups, then food.
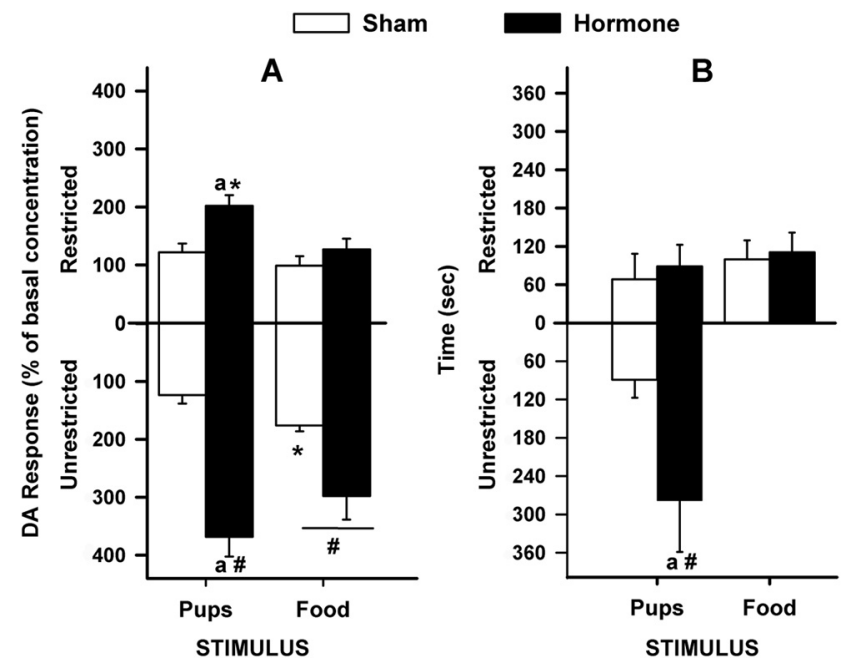

Figure 5. Treatment, stimulus, and access had selective effects on $(\boldsymbol{A}) \mathrm{DA}$ that were unrelated to $(\boldsymbol{B})$ behavior in the OVX female rat (Experiment 2). $\boldsymbol{A}$, DA response data (mean \pm SEM) represent average percentage of basal concentration. Hormone-treated females $(n=7)$ had increased pup-evoked DA compared with the sham group $(n=5)$, regardless of access type; however, this effect during unrestricted access was facilitated. During restriction, hormonetreated females had increased pup-evoked compared with food- evoked DA; and during the unrestricted phase, sham-treated females showed the reverse. Both treatment groups showed increased DA responses to unrestricted food compared with restricted access. $\boldsymbol{B}$, Time spent (mean $\pm \mathrm{SEM}$ ) in behaviors directed toward each of the restricted stimuli and during unrestricted pup access. Among hormone-treated females, but not among sham controls, the time spent with unrestricted access to pups was significantly greater than the time spent with pups in the box. ${ }^{a} p<0.05$, treatment difference for pup stimuli during a given access. ${ }^{\#} p<0.05$, access difference for a given treatment and stimulus. ${ }^{*} p<0.05$, stimulus difference for a given treatment and access.

pup and food stimuli (i.e., 5P5F, 10P10F, 5P10F, 10P5F) and only during unrestricted access did postpartum rats show altered time allocation to stimuli. During unrestricted access under all deprivation conditions, postpartum dams spent increased time with pups and decreased time with food compared with (1) the no deprivation condition $(0 \mathrm{POF}$, average across the $4 \mathrm{~d}),(2)$ the restricted access to stimuli, and (3) each other. In the maximal (i.e., 10P10F) pup and food deprivation condition, postpartum dams had further decreases in time allocated to the side associated with the opened food box (Fig. 6). The restricted stimuli did not generate unequal time allocation either before or after deprivation conditions or between the two stimuli.

\section{Discussion}

The present study demonstrates that pup stimuli can elicit accumbal DA release in hormonally primed rats without actual pup interactions. Unlike nonprimed females, these hormonally primed DA responses were independent of the females' previous pup experience, observed with distal pup stimuli, and expressed in the absence of maternal behavior. Relative to DA patterns in untreated control females, priming by parturition-like hormones suppressed basal DA levels in the postpartum or hormonally treated virgin animals. As well, pup presentation results in large DA increases relative to baseline. In general, lower baseline concentrations were associated with greater pup-evoked DA responses. Hence, the hormonally induced basal DA suppression may facilitate the DA responses to pups. Although previous evidence suggests that DA responses correlate with pup sniffing (Afonso et al., 2009) or pup licking (Afonso et al., 2009, 2011), the present results indicate DA responses can occur independently of the animals' prior maternal experience or the exhibition of many of the maternal consummatory behaviors (e.g., licking, retrieving).

The strong association between pups and pup-predicting cues develops quickly during the early postpartum period under the influence of hormones (Magnusson and Fleming, 1995; Lee et al., 2000; Mattson et al., 2001; Seip and Morrell, 2007, 2009; Seip et al., 2008; Pereira and Morrell, 2010). Primed females come to prefer pups to many other stimuli, effects not seen in the inexperienced nonmaternal virgin animal (Fleming et al., 1980, 1989; Fleming and Luebke, 1981; Fleming and Walsh, 1994; Magnusson and Fleming, 1995; Lee et al., 2000; Mattson et al., 2001; Afonso et al., 2009, 2011). A similar hormonally induced preference can also be seen in the sexual context (Young et al., 1935; Boling et al., 1938; Afonso and Pfaus, 2006) where female rats tend to spend more time with, and bar press more frequently for, sexually active males during proestrus than at other times in the cycle (Bermant, 1961; Bolles et al., 1968). Following appropriate hormonal priming, the willingness of females to traverse electric grids, learn to bar press, and develop a conditioned place preference for appropriate reproductive stimuli (i.e., pups or males) are mediated through dopaminergic ventral tegmental area-NAC mechanisms (Berridge and Robinson, 1998; Everitt and Robbins, 2005).

Maternal responsiveness in female rats is dependent on pregnancy/parturition hormones acting on the medial preoptic area (Numan et al., 1977, 2006; Rosenblatt et al., 1998; Numan and Insel, 2003). It is likely that through either glutamatergic or oxytocinergic projections from the medial preoptic area/bNST to mesolimbic DA neurons in the ventral tegmental area, lead to facilitatory actions of the mesolimbic DA reward circuitry to enhance maternal behavior (Numan and Insel, 2003; Afonso et al., 2009, 2011 Numan and Stolzenberg, 2009; Shahrokh et al., 2010). Our data suggest that hormones not only facilitate actions of the DA system to enhance maternal behavior in the experienced mother, in the absence of pup experience these hormones may ensure that maternal behavior develops. A dissociation between postpartum and hormonally treated females emerged when basal DA concentrations were partialled out of the stimulus-induced 


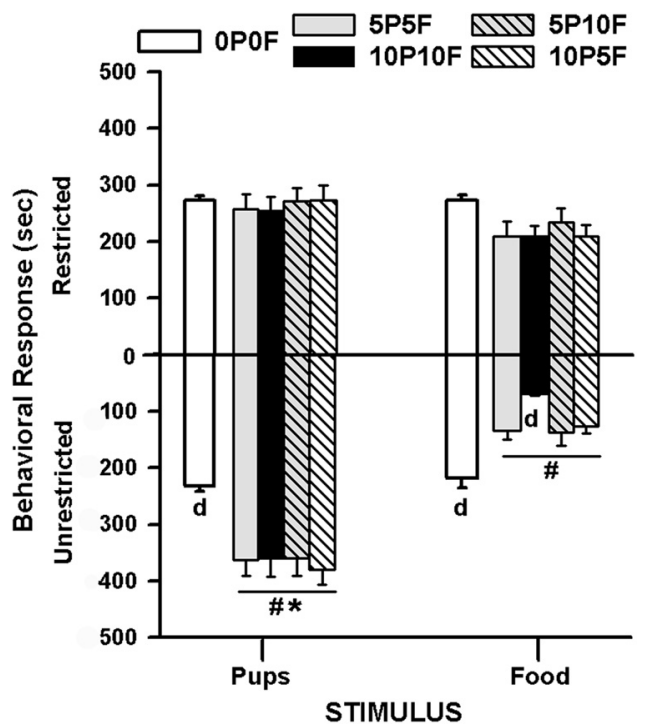

Figure 6. For recently postpartum female rats $(n=16)$, mean ( \pm SEM) time spent on a given side with simultaneous access to pups and food in a restricted and then unrestricted manner (Experiment 3). Postpartum rats show altered time allocation to the stimuli only during unrestricted access and after 5 or $10 \mathrm{~h}$ deprivation from pup (P) and food (F) stimuli (i.e., 5P5F, 10P10F, 5P10F, 10P5F). During unrestricted access, postpartum dams spent increased time with pups and decreased time with food compared with: (1) the no deprivation condition (OPOF, average across the $4 \mathrm{~d}$ ), (2) the restricted access to stimuli, and (3) each other. When both pup and food deprivations were maximal (i.e., 10P10F), postpartum dams had further decreases in time spent on the side associated with unrestricted food stimuli. ${ }^{d} p<0.05$, different from other deprivation conditions during unrestricted access for a given stimulus. After deprivation: ${ }^{*} p<0.05$, access difference for a given stimulus; and ${ }^{*} p<0.05$, unrestricted stimulus difference.

DA responses. Whereas covarying basal concentrations did not influence the statistical outcomes comparing parities on pup-evoked DA responses, this analysis eliminated all significant differences between the hormonally treated and control OVX groups. The difference between postpartum and hormonally primed females most likely was a result of actual pup experience differences between the two conditions. Postpartum females had had $24-48$ h of postparturition pup experience, whereas all other groups were pup-naive at time of sampling. Thus, in addition to hormonal suppression of basal DA levels, pup experience can modify DA signals to pups over and above the hormonal effects on basal DA.

Hormonal effects on the DA reward system most likely involve the ability of gonadal steroid hormones, especially estrogens, to alter the release and metabolism of biogenic amines (DuPont et al., 1981; McEwen and Parsons, 1982; Thompson and Moss, 1994; McEwen and Alves, 1999). For example, chronic estrogen priming increases NAC $\mathrm{D}_{2}$ DA receptors, enhances binding on $\mathrm{D}_{2}$ DA receptors and DA transporter density, all of which could result in lower basal DA concentrations and an increase in stimulus-evoked DA release and excitability of receptors on DA terminals (Di Paolo et al., 1982a,b, 1986, 1988; Morissette et al., 1992; Thompson and Moss, 1994; Becker, 1999; Lammers et al., 1999; Zhou et al., 2002; Lonstein et al., 2003; Becker and Hu, 2008; Chavez et al., 2010). The synergistic effects of these multiple dopaminergic adaptations after chronic estrogen likely influence the pup-evoked DA responses by acting to suppress chronic basal levels. Additionally, progesterone interacts with estradiol and possibly affects parturitional DA mechanisms as it does within other contexts (Russo et al., 2003).

Hormonally primed females will exhibit formerly unfamiliar maternal activities quickly (Mayer and Rosenblatt, 1979, 1980;
Bridges, 1984; Stern and McDonald, 1989). For example, most hormone-treated rats will approach and lick pups on their first exposure to a litter and occasionally will retrieve a pup (Bridges, 1984; Afonso et al., 2009). In pup-naive cycling females and untreated OVX females given foster pups, these behaviors are rarely observed. This sensitivity toward pups is observed during preference tests (Afonso et al., 2009, 2011); females of varying hormonal states were given simultaneous access to pups and unlimited food rewards in the dialysis chamber. Postpartum dams and hormone-treated females with homecage pup experience ( 1 and 2-6 d, respectively) ignored food entirely to interact with pups. Pup-naive hormone-treated females alternated between eating and pup investigations. In contrast, nonhormonally primed controls actively avoided the pups and remained at the neighboring food dispenser, regardless of continuous homecage experience with donor pups. These results are reminiscent of other observations (Fleming et al., 1980, 1989; Fleming and Luebke, 1981; Magnusson and Fleming, 1995; Afonso et al., 2009, 2011) showing that virgin animals initially withdraw from pups, but with continuous pup exposure, approach behavior is observed. Thus, hormones play an important role to influence pupbiased behaviors, and pup experience under hormonal priming can further modify these behavioral responses.

One prominent idea is that DA receptor activation in the NAC constitutes an element of the neural computation of the "effort" that is required to obtain reward (Montague et al., 2004; Salamone et al., 2007; Floresco et al., 2008; Phillips et al., 2008). Numerous studies show that in male rats reward-seeking tasks requiring high degrees of effort are disrupted by reduced DA function in the NAC, whereas similar tasks that require less effort are much less affected (Cousins et al., 1996; Aberman and Salamone, 1999; Salamone et al., 2007). Recently, it has been shown that estradiol exerts modulatory control over cost-benefit decision-making in females (Uban et al., 2012). OVX rats chose to expend more effort for a larger reward, and this effect was reversed by a single high dose of estradiol. These data suggest that estradiol given intermittently appears to shift biases related to decision-making.

During dialysis, both postpartum and hormone-treated females show a greater preference for pups (over food) under unrestricted conditions. When tested in a larger arena, this enhanced preference occurred regardless of the amount of pup or food deprivation in postpartum dams. When both unrestricted pup and food stimuli were given simultaneously, postpartum females consumed the food rewards more quickly (data not shown) after deprivation, resulting in increased time available to spend with the pups. These results suggest that the food-related side could no longer generate food-seeking behavior when permitting active maternal responding, as time allocation is viewed as a critical behavioral marker of reinforcement value (Gallistel and Gibbon, 2000; Cousins et al., 2002). Preventing access to pups appears to diminish the robust preference observed in postpartum females. For example, placing a Plexiglas barrier to prevent postpartum rats from touching or retrieving pups delivered with each bar-press response extinguishes bar pressing in an operant apparatus (Lee et al., 2000). Presently, despite the inability to perform behavioral responses toward pups (e.g., licking, retrieval), a robust DA response was provoked by distal pup cues after hormonal priming, even in the pup-naive females. This result contrasts with findings showing that restricting access to palatable food in opaque boxes is ineffective at stimulating DA responses in the NAC shell (present findings), even after food deprivation (Bassareo and Di Chara, 1999a,b). 
Together, our data demonstrate that, in hormonally primed females, distal pup cues evoke DA responses without prior pup experience, ongoing behavioral responses, or clear evidence that pups have a priori or hormonally mediated salience. The results suggest that NAC DA response reflects a state of responsiveness related to basal DA suppression in the hormonally primed female rat. Hormones associated with the early postpartum period increase the capacity of pup properties to influence the DA system and contribute to the development of initial appetitive responses through heightened responsiveness of NAC DA. As a result of reduced basal DA, a DA signal related to pup stimuli may be sharpened, thereby enhancing the initial pup experience such that saliency develops. Thus, hormones may bias the DA system to respond to distal pups cues (olfactory, vocalization, movement), providing a mechanism to promote maternal behavior.

\section{References}

Aberman JE, Salamone JD (1999) Nucleus accumbens dopamine depletions make rats more sensitive to high ratio requirements but do not impair primary food reinforcement. Neuroscience 92:545-552. CrossRef Medline

Afonso VM, Pfaus JG (2006) Hormonal and experiential control of femalemale mounting in the female rat. Horm Behav 49:30-37. CrossRef Medline

Afonso VM, King S, Chatterjee D, Fleming AS (2009) Hormones that increase maternal responsiveness affect accumbal dopaminergic responses to pup- and food- stimuli in the female rat. Horm Behav 56:11-23. CrossRef Medline

Afonso VM, King SJ, Novakov M, Burton CL, Fleming AS (2011) Accumbal dopamine function in postpartum rats that were raised without their mothers. Horm Behav 60:632-643. CrossRef Medline

Bassareo V, Di Chiara G (1999a) Modulation of feeding-induced activation of mesolimbic dopamine transmission by appetitive stimuli and its relation to motivational state. Eur J Neurosci 11:4389-4397. CrossRef Medline

Bassareo V, Di Chiara G (1999b) Differential responsiveness of dopamine transmission to food-stimuli in nucleus accumbens shell/core compartments. Neuroscience 89:637-641. CrossRef Medline

Becker JB (1999) Gender differences in dopaminergic function in striatum and nucleus accumbens. Pharmacol Biochem Behav 64:803-812. CrossRef Medline

Becker JB, Hu M (2008) Sex differences in drug abuse. Front Neuroendocrinol 29:36-47. CrossRef Medline

Bermant G (1961) Response latencies of female rats during sexual intercourse. Science 133:1171-1173.

Berridge KC, Robinson TE (1998) What is the role of dopamine in reward: hedonic impact, reward learning, or incentive salience? Brain Res Brain Res Rev 28:309-369. CrossRef Medline

Boling JL, Young WC, Dempsey EW (1938) Miscellaneous experiments on the estrogen progesterone in induction of heat in the spayed guinea-pig. Endocrinology 23:182-187. CrossRef

Bolles RC, Rapp HM, White GC (1968) Failure of sexual activity to reinforce female rats. J Comp Physiol Psych 65:311-313. CrossRef

Bridges RS (1984) A quantitative analysis of the roles of dosage, sequence, and duration of estradiol and progesterone exposure in the regulation of maternal behavior in the rat. Endocrinology 114:930-940. CrossRef Medline

Bridges RS (1990) Endocrine regulation of parental behavior in rodents. In: Mammalian parenting: biochemical, neurobiological, and behavioural determinants (Krasnegor N, Bridges RS, eds), pp 93-117. New York: Oxford University.

Cagniard B, Beeler JA, Britt JP, McGehee DS, Marinelli M, Zhuang X (2006) Dopamine scales performance in the absence of new learning. Neuron 51:541-547. CrossRef Medline

Champagne FA, Chretien P, Stevenson CW, Zhang TY, Gratton A, Meaney MJ (2004) Variations in nucleus accumbens dopamine associated with individual differences in maternal behavior in the rat. J Neurosci 24:41134123. CrossRef Medline

Chavez C, Hollaus M, Scarr E, Pavey G, Gogos A, van den Buuse M (2010) The effect of estrogen on dopamine and serotonin receptor and trans- porter levels in the brain: an autoradiography study. Brain Res 1321: 51-59. CrossRef Medline

Cousins MS, Atherton A, Turner L, Salamone JD (1996) Nucleus accumbens dopamine depletions alter relative response allocation in a T-maze cost/benefit task. Behav Brain Res 74:189-197. CrossRef Medline

Cousins MS, Roberts DC, de Wit H (2002) GABA(B) receptor agonists for the treatment of drug addiction: a review of recent findings. Drug Alcohol Depend 65:209-220. CrossRef Medline

Di Paolo T, Bédard PJ, Dupont A, Poyet P, Labrie F (1982a) Effects of estradiol on intact and denervated striatal dopamine receptors and on dopamine levels: a biochemical and behavioural study. Can J Physiol Pharmacol 60:350-357. CrossRef Medline

Di Paolo T, Daigle M, Dupont A (1982b) Distribution of dopamine in 35 subregions of the rat caudate-putamen: a high performance liquid chromatography with electrochemical detection analysis. Can J Neurol Sci 9:421-427. Medline

Di Paolo T, Lévesque D, Daigle M (1986) A physiological dose of progesterone affects rat striatum biogenic amine metabolism. Eur J Pharmacol 125:11-16. CrossRef Medline

Di Paolo T, Falardeau P, Morissette M (1988) Striatal D-2 dopamine agonist binding sites fluctuate during the rat estrous cycle. Life Sci 43:665-672. CrossRef Medline

Dupont A, Di Paolo T, Gagné B, Barden N (1981) Effects of chronic estrogen treatment on dopamine concentrations and turnover in discrete brain nuclei of ovariectomized rats. Neurosci Lett 22:69-74. CrossRef Medline

Everitt BJ, Robbins TW (2005) Neural systems of reinforcement for drug addiction: from actions to habits to compulsion. Nat Neurosci Rev 8:1481-1489. CrossRef Medline

Ferris CF, Kulkarni P, Sullivan JM Jr, Harder JA, Messenger TL, Febo M (2005) Pup suckling is more rewarding than cocaine: evidence from functional magnetic resonance imaging and three-dimensional computational analysis. J Neurosci 25:149-156. CrossRef Medline

Fleming AS, Luebke C (1981) Timidity prevents the virgin female rat from being a good mother: emotionality differences between nulliparous and parturient females. Physiol Behav 27:863-868. CrossRef Medline

Fleming AS, Rosenblatt JS (1974) Maternal behavior in the virgin and lactating rat. J Comp Physiol Psychol 86:957-972. CrossRef Medline

Fleming AS, Walsh C (1994) Neuropsychology of maternal behavior in the rat: c-fos expression during mother-litter interactions. Psychoneuroendocrinology 19:429-443. CrossRef Medline

Fleming AS, Vaccarino F, Luebke C (1980) Amygdaloid inhibition of maternal behavior in the nulliparous female rat. Physiol Behav 25:731-743. CrossRef Medline

Fleming AS, Cheung U, Myhal N, Kessler Z (1989) Effects of maternal hormones on 'timidity' and attraction to pup-related odors in female rats. Physiol Behav 46:449-453. CrossRef Medline

Floresco SB, St Onge JR, Ghods-Sharifi S, Winstanley CA (2008) Corticolimbic-striatal circuits subserving different forms of cost-benefit decision-making. Cogn Affect Behav Neurosci 8:375-389. CrossRef Medline

Gallistel CR, Gibbon J (2000) Time, rate, and conditioning. Psychol Rev 107:289-344. CrossRef Medline

Graybiel AM, Aosaki T, Flaherty AW, Kimura M (1994) The basal ganglia and adaptive motor control. Science 265:1826-1831. CrossRef Medline

Hansen S, Harthon C, Wallin E, Löfberg L, Svensson K (1991a) Mesotelencephalic dopamine system and reproductive behavior in the female rat: effects of ventral tegmental 6-hydroxydopamine lesions on maternal and sexual responsiveness. Behav Neurosci 105:588-598. CrossRef Medline

Hansen S, Harthon C, Wallin E, Löfberg L, Svensson K (1991b) The effects of 6-OHDA-induced dopamine depletions in the ventral or dorsal striatum on maternal and sexual behavior in the female rat. Pharmacol Biochem Behav 39:71-77. CrossRef Medline

Hansen S, Bergvall AH, Nyiredi S (1993) Interaction with pups enhances dopamine release in the ventral striatum of maternal rats: a microdialysis study. Pharmacol Biochem Behav 45:673-676. CrossRef Medline

Krehbiel DA, LeRoy LM (1979) The quality of hormonally stimulated maternal behavior in ovariectomized rats. Horm Behav 12:243-252. CrossRef Medline

Lammers CH, D'Souza U, Qin ZH, Lee SH, Yajima S, Mouradian MM (1999) Regulation of striatal dopamine receptors by estrogen. Synapse 34:222-227. CrossRef Medline

Lee A, Clancy S, Fleming AS (2000) Mother rats bar-press for pups: effects of 
lesions of MPOA and limbic sites on maternal behavior and operant responding for pup-reinforcement. Behav Brain Res 108:215-231. CrossRef Medline

Li M, Fleming AS (2002) Psychobiology of maternal behavior and its early determinants in nonhuman mammals. In: Handbook of parenting: Vol 2, Biology and ecology of parenting (Bornstein ED, ed), pp 61-97. Mahwah, New Jersey: Earlbaum.

Lonstein JS, Dominguez JM, Putnam SK, De Vries GJ, Hull EM (2003) Intracellular preoptic and striatal monoamines in pregnant and lactating rats: possible role in maternal behavior. Brain Res 970:149-158. CrossRef Medline

Magnusson J, Fleming AS (1995) Rat pups are reinforcing to the maternal rat: role of sensory cues. Psychobiology 23:69-75.

Mattson BJ, Williams S, Rosenblatt JS, Morrell JI (2001) Comparison of two positive reinforcing stimuli: pups and cocaine throughout the postpartum period. Behav Neurosci 115:683-694. CrossRef Medline

Mayer AD, Rosenblatt JS (1979) Hormonal influences during the ontogeny of maternal behavior in female rats. J Comp Physiol Psychol 93:879-898. CrossRef

Mayer AD, Rosenblatt JS (1980) Hormonal interaction with stimulus and situational factors in the initiation of maternal behavior in nonpregnant rats. J Comp Physiol Psychol 94:1049-1059. Medline

Mayer AD, Rosenblatt JS (1987) Hormonal factors influence the onset of maternal aggression in laboratory rats. Horm Behav 21:253-267. CrossRef Medline

McEwen BS, Alves SE (1999) Estrogen actions in the central nervous system. Endocr Rev 20:279-307. CrossRef Medline

McEwen BS, Parsons B (1982) Gonadal steroid action on the brain: neurochemistry and neuropharmacology. Annu Rev Pharmacol Toxicol 22: 555-598. CrossRef Medline

Moltz H, Lubin M, Leon M, Numan M (1970) Hormonal induction of maternal behavior in the ovariectomized nulliparous rat. Physiol Behav 5:1373-1377. CrossRef Medline

Montague PR, McClure SM, Baldwin PR, Phillips PE, Budygin EA, Stuber GD, Kilpatrick MR, Wightman RM (2004) Dynamic gain control of dopamine delivery in freely moving animals. J Neurosci 24:1754-1759. CrossRef Medline

Morissette M, Garcia-Segura LM, Bélanger A, Di Paolo T (1992) Changes of rat striatal neuronal membrane morphology and steroid content during the estrous cycle. Neuroscience 49:893-902. CrossRef Medline

Numan M, Insel TR (2003) The neurobiology of parental behavior. New York: Springer.

Numan M, Stolzenberg DS (2009) Medial preoptic area interactions with dopamine neural systems in the control of the onset and maintenance of maternal behavior in rats. Front Neuroendocrinol 30:46-64. CrossRef Medline

Numan M, Rosenblatt JS, Komisaruk BR (1977) Medial preoptic area and onset of maternal behavior in the rat. J Comp Physiol Psychol 91:146164. CrossRef Medline

Numan M, Fleming AS, Levy F (2006) Maternal behavior. In: Knobiol and Neill's physiology of reproduction (Neill JD, ed), pp 1921-1993. New York: Raven.

Olazábal DE, Abercrombie E, Rosenblatt JS, Morrell JI (2004) The content of dopamine, serotonin, and their metabolites in the neural circuit that mediates maternal behavior in juvenile and adult rats. Brain Res Bull 63:259-268. CrossRef Medline
Orpen BG, Fleming AS (1987) Experience with pups sustains maternal responding in postpartum rats. Physiol Behav 40:47-54. CrossRef Medline

Paxinos G, Watson C (1986) The rat brain in stereotaxic coordinates, Ed 2. San Diego: Academic.

Pereira M, Morrell JI (2010) The medial preoptic area is necessary for motivated choice of pup- over cocaine-associated environments by early postpartum rats. Neuroscience 167:216-231. CrossRef Medline

Phillips AG, Vacca G, Ahn S (2008) A top-down perspective on dopamine, motivation and memory. Pharmacol Biochem Behav 90:236-249. CrossRef Medline

Rosenblatt JS (1967) Nonhormonal basis of maternal behavior in the rat. Science 156:1512-1514. CrossRef Medline

Rosenblatt JS, Olufowobi A, Siegel HI (1998) Effects of pregnancy hormones on maternal responsiveness, responsiveness to estrogen stimulation of maternal behavior, and the lordosis response to estrogen stimulation. Horm Behav 33:104-114. CrossRef Medline

Russo SJ, Festa ED, Fabian SJ, Gazi FM, Kraish M, Jenab S, QuinonesJenab V (2003) Gonadal hormones differentially modulate cocaineinduced conditioned place preference in male and female rats. Neuroscience 120:523-533. CrossRef Medline

Salamone JD, Correa M, Farrar A, Mingote SM (2007) Effort-related functions of nucleus accumbens dopamine and associated forebrain circuits. Psychopharmacology 191:461-482. CrossRef Medline

Seip KM, Morrell JI (2007) Increasing the incentive salience of cocaine challenges preferences for pup- over cocaine-associated stimuli during early postpartum: place preference and locomotor analyses in the lactating female rat. Psychopharmacology 194:309-319. CrossRef Medline

Seip KM, Morrell JI (2009) Transient inactivation of the ventral tegmental area selectively disrupts the expression of conditioned place preference for pup- but not cocaine-paired contexts. Behav Neurosci 123: 1325-1338. CrossRef Medline

Seip KM, Pereira M, Wansaw MP, Reiss JI, Dziopa EI, Morrell JI (2008) Incentive salience of cocaine across the postpartum period of the female rat. Psychopharmacology 199:119-130. CrossRef Medline

Shahrokh DK, Zhang TY, Diorio J, Gratton A, Meaney MJ (2010) Oxytocindopamine interactions mediate variations in maternal behavior in the rat. Endocrinology 151:2276-2286. CrossRef Medline

Stern JM, McDonald C (1989) Ovarian hormone-induced short-latency maternal behavior in ovariectomized virgin Long-Evans rats. Horm Behav 23:157-172. CrossRef Medline

Thompson TL, Moss RL (1994) Estrogen regulation of dopamine release in the nucleus accumbens: genomic- and nongenomic-mediated effects. J Neurochem 62:1750-1756. CrossRef Medline

Uban KA, Rummel J, Floresco SB, Galea LA (2012) Estradiol modulates effort-based decision-making in female rats. Neuropsychopharmacology 37:390-401. CrossRef Medline

Wiesner BP, Sheard NM (1933) Maternal behaviour in the rat. Edinburgh: Oliver and Boyd.

Young WC, Dempsey EW, Myers HI (1935) Cyclic reproductive behavior in the female guinea pig. J Comp Psychol 19:313-335. CrossRef

Zhou W, Koldzic-Zivanovic N, Clarke CH, de Beun R, Wassermann K, Bury PS, Cunningham KA, Thomas ML (2002) Selective estrogen receptor modulator effects in the rat brain. Neuroendocrinology 75:24-33. CrossRef Medline 